\title{
Contribuição para a análise das interferềncias mercadológicas nos currículos escolares
}

LUIZ ANTÔNIO CUNHA Universidade Federal do Rio de Janeiro

Este artigo almeja contribuir para o conhecimento do modo como se definem os currículos escolares no Brasil, com ênfase no setor público. O termo currículo é empregado aqui em sua acepção restrita, designando tão somente as disciplinas, os temas e conteúdos da atividade escolar. Assumindo o pressuposto de que a débil autonomia do campo educacional brasileiro propicia a intervenção de forças externas a ele, o texto focaliza duas vertentes das pressões dos mercados - a ideológica e a econômica - como relevantes para o entendimento da heteronomia do campo educacional.

Uma advertência deve ser feita desde já. O texto não faz distinção entre as "boas" e as "más" interferências, nem entre seus agentes legítimos e ilegítimos, o que não quer dizer que essa distinção não deva ser feita. Muito pelo contrário. Se assim procedemos, neste artigo, foi porque, mais do que defender uma certa pressão sobre os currículos escolares, enquanto atacamos outras, o objetivo foi mostrar como os sistemas educacionais estão, no Brasil, submetidos a tais e tantas pressões para atenderem a interesses de distintos agentes sociais, que a consequência geral 
não poderia ser outra senão o enfraquecimento da ação escolar, seja pelo chamado enciclopedismo, seja pela contradição curricular. ${ }^{1}$

Cumpre informar ao leitor de uma abordagem que não será feita aqui. Em momento algum serão tratadas as demandas dos empregadores públicos e privados para a qualificação da força de trabalho pela escola. Correndo o risco de antecipar uma questão desenvolvida mais adiante, consideremos o conhecimento de língua estrangeira, especificamente da língua inglesa. Seja para a leitura de manuais, para a correspondência escrita ou digitalizada, para contatos diretos em função do comércio exterior, os empregadores aumentam a demanda de força de trabalho com diferentes graus de domínio da língua inglesa. Desse tipo de requerimento, nada será mencionado neste artigo. ${ }^{2}$ Mas, se houvesse pressão de editores ou importadores de livros ou outros meios de ensino para uso escolar, aí, sim, tal pressão estaria entre nossos objetivos. Em duas palavras, não trataremos da pressão dos mercados sobre os produtos da escola, trataremos de pressões sobre os indutos, numa abordagem empírica e analítica.

A luta pela autonomização do campo educacional não é nova, no Brasil. O "Manifesto dos Pioneiros da Educação Nova", de 1932, já trazia um diagnóstico e uma terapêutica para esse problema. Para os pioneiros, o campo educacional era o lugar do empirismo e da improvisação: "Tudo fragmentado e desarticulado". A causa disso estaria na falta da determinação dos fins da educação (aspecto filosófico e social) e da aplicação (aspecto técnico) dos métodos científicos aos problemas da educação. Isso tudo seria resultado, por sua vez, de deficiências do próprio campo educacional, isto é, da total ausência de uma cultura universitária, assim como da formação meramente literária de nossas elites.

Os autores do "Manifesto" apontavam a dificuldade da autonomização da educação pública diante do Estado. De um lado, reclamaram autonomia, de outro, disseram que, sem o apoio político do Estado, a autonomia que se desejava não seria possível. O Estado teria responsabilidade na geração da situação atual da educação, porque nem sempre soube ou não quis impedir a atuação dos interesses escusos e as intromissões indevidas. No entanto, somente o Estado teria o poder de criar condições para a autonomia desejada em suas diversas dimensões. Ao Estado caberia, "evidentemente", a organização dos meios para garantir o direito de todos os indivíduos à educação. Isso se efetivaria mediante a elaboração e a implementação de um plano geral de educação, de estrutura orgânica.

1 A mais flagrante contradição no currículo da educação básica é a que contrapõe a Biologia, que tem na Teoria da Evolução das Espécies seu eixo de desenvolvimento, e o Ensino Religioso, que comporta programas criacionistas, a critério dos agentes confessionais.

2 A complexidade da relação aqui estabelecida foi evidenciada por busca na internet, pelo Google, que indicou mais de dois milhões de referências aos termos "currículo + mercado", acessadas em 5/7/2011. É claro que os conteúdos mais diversos foram rastreados nessa busca, com nítida predominância prescritiva. 
Além da autonomia diante dos governos, o "Manifesto" clamou por autonomia para uma atuação definida a partir de dentro do campo educacional: seria necessário que os educadores dispusessem de uma ampla autonomia técnica, administrativa e econômica. Só assim a "direção da função educacional" teria os meios materiais para realizar seus fins próprios.

No entanto, os meios materiais não deveriam resumir-se às verbas nos orçamentos, pois elas sempre estariam sujeitas às crises das finanças dos governos ou às oscilações do interesse dos governantes pela educação. Para que a autonomia existisse efetivamente, seria preciso instituir um fundo educacional, composto de patrimônio, de impostos específicos e de rendas próprias. Todos esses recursos seriam administrados e aplicados no desenvolvimento da obra educacional pelos órgãos de ensino incumbidos de sua direção.

A bibliografia recente traz contribuições relevantes para a compreensão das dificuldades de construção da autonomia do campo educacional no Brasil, especialmente no setor público, muito além do que os pioneiros podiam imaginar. Dois artigos são aqui evocados, ambos publicados no n. 108 de Educação É Sociedade, integrantes de dossiê sobre as relações entre as esferas pública e privada. O editorial desse número da revista assinalou que as alterações ocorridas na configuração dos Estados nacionais, bem como a recente crise do capitalismo, em escala mundial, levaram à emergência e à proliferação de novas ou de renovadas formas de simbiose entre as duas esferas. Essas formas simbióticas, por sua vez, definem-se mediante novos marcos regulatórios. Vejamos duas das contribuições desse dossiê.

Romualdo Portela de Oliveira (2009) destacou o controle de instituições privadas de educação por grandes grupos oligopolísticos, empresas estrangeiras de educação e fundos financeiros, inclusive mediante o lançamento de ações nas bolsas de valores. Sobre o setor educacional privado no Brasil, nos primeiros anos do século XXI, disse ele:

No início desta década, ao se identificar que o setor de educação superior sofreria rápida expansão, a atenção dos fundos de investimento voltou-se para essa área, ocasião em que foram constituídos os primeiros fundos de investimento exclusivamente direcionados à educação. Esses fundos têm condições de injetar altas quantias em empresas educacionais, ao mesmo tempo em que empreendem ou induzem processos de reestruturação das escolas nas quais investem, por meio da redução dos custos, da racionalização administrativa, em suma, da "profissionalização" da gestão das instituições de ensino, numa perspectiva claramente empresarial. (Oliveira, 2009, p. 743)

A adoção de formas de gestão cada vez mais capitalistas, nas instituições privadas de ensino, potencializam processos que já vinham desenvolvendo-se no âmbito da educação pública, que fica mais permeável às interferências dos mercados. 
No que diz respeito ao emprego do termo mercado, este artigo tem posição distinta da corrente. Nesta, o mercado concerne tão somente à acumulação de capital no sentido econômico do termo. A despeito da importância desse sentido, entendemos que há outros que precisam ser levados em conta, sob pena de se restringir, demasiadamente, a múltipla acepção do termo. $\mathrm{Na}$ perspectiva de Pierre Bourdieu (1983), o termo mercado é aqui empregado em acepção ampla, além de sua corrente aplicação econômica. Daí que, antes de tudo, passaremos a falar de mercados, no plural.

Para o sociólogo francês, mercados e campos são categorias correlatas. Campos são mercados com formas próprias de capital, cada um a seu modo - econômico, cultural, social ou simbólico. Todo campo é constituído sobre um mercado, embora nem todo mercado constitua um campo. ${ }^{3}$ Em cada campo, agentes dotados de diferentes valores do capital que lhe é próprio disputam sua acumulação e o monopólio de sua reprodução. Cada campo tem pretensão à autonomia, embora uns sejam mais autônomos do que outros, conforme sejam mais próprias as normas que os regem. No Brasil, mais do que em outros países, o campo educacional é um exemplo de autonomia pretendida mas não realizada, pois sofre interferências de outros campos ou, simplesmente, de outros mercados.

Essas interferências são múltiplas. Para simplificar, as agrupamos em duas vertentes, as ideológicas e as econômicas.

A vertente ideológica abrange a instrumentalização de instituições educacionais para a inculcação de valores e padrões de comportamento presumidamente legítimos por entidades não propriamente educacionais, tais como as religiosas. Mesmo após a separação Estado-Igreja pela República, proclamada em 1889, as interferências religiosas do clero católico retornaram explícita e legalmente à educação pública em 1931, e sofreram um recrudescimento a partir da Assembleia Nacional Constituinte de 1987-1988, como efeito reativo do crescimento das Igrejas evangélicas e dos movimentos laicos. Ligadas às propostas religiosas para a educação, especialmente a educação pública, setores políticos situados à direita do espectro ideológico pretendem reeditar a Educação Moral e Cívica, que caracterizou as ditaduras de 1937-1945 e 1964-1985. Além disso, pela direita e pela esquerda, prosperam propostas da inserção de conteúdos, disciplinares ou não, dos Direitos Humanos nos currículos escolares, nas quais as tendências religiosas são menos visíveis ou mesmo inexistentes.

A vertente econômica da pressão sobre o campo educacional compreende tanto a venda de mercadorias para consumo das instituições escolares (a oferta

3 Como exemplos dessa distinção podem ser mencionados o mercado de drogas, que não pode ser compreendido totalmente pelas regras do campo econômico, e o mercado matrimonial, que, objeto de tanta dissimulação, é dificilmente assim entendido. 
gerando a demanda), quanto os contratos ou convênios com empresas e organizações não governamentais. Vitoriosas tais pressões, as redes públicas de ensino compram das empresas privadas livros, computadores, sistemas apostilados de ensino e outros produtos. As empresas passam a contar com encomendas de grandes volumes de mercadorias e pagamento assegurado. Organizações não governamentais passam a ter receitas garantidas e poder de atuar sobre o ensino público mediante consultorias, treinamentos, avaliação e até mesmo a gestão de redes inteiras. Não menos importantes são as leis que determinam a inserção de disciplinas nos currículos escolares, às quais correspondem monopólio do magistério pelos diplomados em certos cursos de licenciatura, modificando-se, em consequência, os planos de carreira do professorado municipal e/ou estadual e/ou federal. Concursos são abertos para o preenchimento das novas vagas e a redefinição da carga horária das disciplinas é o resultado inevitável dessas providências.

A distinção dessas vertentes é útil para efeitos analíticos, mas é preciso estar atento para a tentação de sua reificação: os processos concretos não distinguem uma da outra. Assim, a venda de mercadorias, a reserva de mercado de trabalho e os projetos de socialização político-ideológica configuram os currículos escolares tão ou mais decisivamente do que os embates das concepções propriamente pedagógicas.

Passemos, então, a tratar de cada uma das vertentes de interferência dos mercados no campo educacional.

\section{A VERTENTE IDEOLÓGICA}

Vamos começar pelo meio: é pelos projetos ou indicações de lei, apresentados por deputados e senadores, que se exerce a pressão ideológica dos mercados sobre os currículos escolares, especialmente nas redes públicas de educação. Com ou sem campanha prévia na imprensa, tais projetos consistem na criação de disciplinas ou conteúdos curriculares que expressam a demanda de algum partido ideológico. ${ }^{4}$

As Igrejas cristãs são os mais importantes partidos ideológicos na disputa pelo controle curricular na educação brasileira. Antes de tudo, a Igreja Católica, que durante séculos desfrutou do privilégio de religião de Estado. Com a proclamação da República, a Igreja Católica foi separada do Estado, que determinou o caráter laico (dito leigo) do ensino público.

4 A noção de partido ideológico é calcada na análise de Antonio Gramsci a Croce como homem de partido. O filósofo sardo distinguiu o partido político, entendido como organização prática para o enfrentamento de problemas da vida nacional ou internacional, do partido ideológico, concernente à "ideologia geral, superior aos vários agrupamentos mais imediatos" (Gramsci, 1978, p. 205). 
A atitude da Igreja Católica ${ }^{5}$ com o ensino público tem sido, ao longo dos anos, marcada por conflitos. No século XIX, quando os países da Europa começaram a organizar sistemas estatais de educação escolar, bulas papais proibiram os fiéis de matricular neles seus filhos. Constatada a inviabilidade da proibição, a instituição passou a exigir que os governos transferissem recursos financeiros para cobrir as mensalidades das crianças pobres nas escolas privadas, para fazer valer o direito dos pais de escolher o tipo de educação dos filhos. Esta última consigna está em vigor na legislação brasileira desde a primeira Lei de Diretrizes e Bases da Educação Nacional (LDB), de 1961. A segunda, de 1996, apesar de determinar que os recursos públicos sejam destinados às escolas públicas, abre exceção para as instituições privadas sem fins lucrativos, dentre as quais especifica as confessionais.

Já que não foi possível frear a criação e o crescimento dos sistemas públicos de ensino, a Igreja Católica passou a exigir que eles inserissem conteúdos religiosos nos currículos, na forma de disciplina específica. Foi o que se fez no Brasil, a partir de 1931, quando o decreto n. 19.941 facultou o oferecimento, nos estabelecimentos públicos de ensino primário, secundário e normal, da instrução religiosa.

A vitória alcançada pela Igreja Católica com a promulgação desse decreto veio a ser potencializada na Constituição de 1934. Substituindo antigo projeto de se fundar um Partido Católico, o cardeal Sebastião Leme patrocinou a criação, em 1932, da Liga Eleitoral Católica (LEC), com o objetivo de alistar, organizar e instruir os eleitores, em todo o país, bem como canalizar seus votos para os candidatos que aceitassem o programa da Igreja e prometessem defendê-lo na Assembleia Constituinte que viria a ser formada. O sucesso dessa estratégia política foi total, pois a maioria dos candidatos apoiados pela LEC se elegeram. Com a forte bancada que apoiava o programa da LEC, a Assembleia mostrou-se logo favorável ao Ensino Religioso nas escolas públicas, de maneira ainda mais próxima das demandas da Igreja Católica.

A liderança contra a plataforma Católica na Constituinte foi do deputado Guaraci Silveira, eleito pelo Partido Socialista Brasileiro, na bancada de São Paulo. Silveira era pastor Metodista, numa época em que os protestantes de todas as confissões não ultrapassavam os $2 \%$ da população brasileira. A despeito dessa inexpressiva presença quantitativa, os Evangélicos, em especial os Metodistas, procuravam basear-se no prestígio de suas escolas para reivindicar maior espaço político-ideológico no campo educacional. Ou, pelo menos, de não tê-lo reduzido. $\mathrm{Na}$ argumentação contra o artigo que tornava a oferta do Ensino Religioso obrigatória nas escolas públicas, embora facultativo para os alunos, Silveira empregou argumentos que mostravam que tal medida atendia apenas aos interesses hegemônicos da Igreja Católica e, na prática, inviabilizava o ensino de outras religiões.

5 Como Igreja católica designamos, aqui, o conjunto dos dirigentes dessa instituição, em especial o alto clero. Não nos referimos aos fiéis, isto é, aos católicos. 
Com o apoio dos socialistas, liberais e maçons, Silveira apresentou emenda substituindo o Ensino Religioso pela Educação Moral e Cívica. A reação católica foi orquestrada e maciça. Sob o lema de que "sem religião não há moral", as emendas de Silveira foram fragorosamente derrotadas nessa como nas demais questões que envolviam o reforço do poder político da Igreja Católica (Almeida, 2002).

Como resultado, a possibilidade de associação entre Igreja e Estado foi introduzida no texto constitucional. No mesmo artigo em que se vedava aos governos federal, estaduais e municipais terem "relação de aliança ou de dependência com qualquer culto ou Igreja", acrescentava-se a ressalva "sem prejuízo da colaboração recíproca em prol do interesse coletivo".

A Constituição de 1934 foi, então, promulgada com um artigo sobre o Ensino Religioso (ao invés da instrução religiosa, do decreto de 1931). As escolas públicas primárias, secundárias, profissionais e normais eram obrigadas a oferecê-lo, pois tal ensino constituiria "matéria dos horários". Todavia, a presença continuava facultativa para os alunos, com os pais ou responsáveis podendo manifestar sua preferência pelas distintas confissões religiosas.

Desde 1934, todas as Constituições brasileiras, inclusive a de 1988, em vigor, trazem determinações de oferta da disciplina Ensino Religioso nas escolas públicas, aliás, a única disciplina escolar mencionada nas Cartas Magnas.

As Leis de Diretrizes e Bases da Educação (LDBs) foram expressões legislativas de projetos da Igreja Católica no tocante à educação pública e privada, mas traziam limitações. Para o que interessa a este texto, basta mencionar que a LDB-1961 trouxe um dispositivo inédito no artigo que regulamentou o Ensino Religioso nas escolas públicas. Como parte das composições realizadas na Câmara dos Deputados, a lei foi promulgada com a determinação de impedimento de uso de recursos públicos para essa disciplina. Dez anos depois de promulgada a LDB-1961, a lei n. 5.692/1971 suprimiu esse impedimento. A LDB-1996 repetiu aquela restrição, mas, dessa vez, ela foi suprimida mais prontamente: a lei n. 9.475/1997, promulgada sete meses depois daquela, modificou seu artigo 33 em vários pontos. Destacamos a supressão do impedimento do uso de recursos públicos para financiar o Ensino Religioso (pagar os professores, por exemplo) e a declaração de que essa disciplina constitui "parte integrante da formação básica do cidadão". Aprovada às vésperas da visita do papa João Paulo II ao Brasil, a lei foi calcada em três projetos, do MEC e de dois deputados, sintetizados no substitutivo do deputado padre católico Roque Zimermann.

A disputa deslocou-se entre a oferta ou não do Ensino Religioso nas escolas públicas pela modalidade de seu ensino, confessional ou não confessional, esta última propiciadora de composição política de curto prazo entre os cleros Católico e Evangélicos, especialmente os pentecostais, em acelerado crescimento. ${ }^{6}$ Mas essa

6 Nas últimas oito décadas, o campo religioso tem se alterado profundamente no Brasil. Em linhas gerais, quatro são os vetores dessas mudanças: a proporção dos adeptos do 
composição foi inviabilizada, na prática, pela assinatura da concordata entre o Brasil e a Santa Sé, em 2009, que previu a oferta de "Ensino Religioso, Católico e de outras confissões". Em contraofensiva, projetos de lei foram apresentados no Congresso Nacional em defesa do interconfessionalismo, dentre os quais o PL n. 309/2011, de autoria do pastor-deputado Marco Feliciano (PSC-SP).

Desde o início do período republicano, a posição da Igreja Católica permanece a mesma: o Estado tem de estar a serviço da religião, inclusive a escola pública, cujo currículo deve incluir o Ensino Religioso custeado pelos orçamentos governamentais. Os Evangélicos, por sua vez, não têm tido posição homogênea, já que não estão submetidos a uma estrutura burocrática unificada. Algumas Igrejas mantêm posição a favor da laicidade do ensino público, outras, justamente as que mais crescem e parecem dispostas a ocupar o lugar dominante da Católica de outrora, defendem a inserção do Ensino Religioso nas escolas públicas. Para elas, o interconfessionalismo é uma transição oportuna durante o período de crescimento.

A posição do pastor Metodista Guaraci Silveira, na Assembleia Constituinte de 1933-1934, de substituir o Ensino Religioso nas escolas públicas pela Educação Moral e Cívica, já não prospera. No seu lugar, esta disciplina tem sido uma auxiliar daquela. Durante o regime autoritário de 1964-1985, essa simbiose nem mesmo foi disfarçada no parecer n. 94/71, do Conselho Federal de Educação, de autoria do arcebispo Luciano Cabral Duarte, que determinou seus conteúdos nos três níveis de ensino. Suprimida a obrigatoriedade da Educação Moral e Cívica pela lei n. 8.663/1993, essa disciplina ficou ausente da segunda LDB. No entanto, seu retorno tem sido defendido a partir da direita do espectro ideológico.

Daniela Patti do Amaral (2007) realizou pesquisa sobre os projetos de lei em tramitação no Congresso Nacional, apresentados no período 1997-2006. Descontados os que haviam sido arquivados, ela encontrou sete projetos em tramitação no fim daquele período. Dois deles tratavam diretamente da recriação de disciplinas correlatas a serem inseridas nos currículos do ensino fundamental. O deputado Milton Monti (PR-SP) pretendia a inserção de Organização Social e Política do Brasil; o deputado Paulo Lima (PMDB-SP) queria a inclusão de Educação Moral e Cívica. Menos pretensiosos, outros deputados defendiam a inclusão de componentes curriculares que combinavam aqueles conteúdos com formas mais amplas: Chico Sardelli (PFL-SP) queria a ética, moral e civismo no ensino fundamental; Fernando Zuppo (PDT-SP), ética e cidadania em todos os

catolicismo caiu expressivamente, de 93\%, em 1960, para 73,4\%, em 2000; as Igrejas evangélicas cresceram muito, passando de 4\% de adeptos, em 1960, para 15,4\% em 2000; os adeptos das religiões afro-brasileiras reduziram-se bastante, em proveito das confissões evangélicas, fenômeno de difícil medida; a parcela dos declarantes "sem religião" passou de 0,5\% em 1960 para 7,4\% em 2000 (Jacob, 2003). 
níveis do ensino; Paes Landim (PTB-PI), valores morais, éticos, cívicos e da nacionalidade no ensino fundamental; Dr. Talmir (PV-SP), ética, cidadania e direitos humanos no ensino fundamental e médio; e Humberto Souto (PPS-MG), valores éticos e cidadania no ensino fundamental.

Embora nem todas as propostas de inserção de conteúdos curriculares na educação básica, pela vertente ideológica, sejam provenientes da direita do espectro ideológico, são essas que predominam. Todavia, há iniciativas para a inclusão do tema dos Direitos Humanos, baseado numa moral laica, sintonizado, aliás, com as Diretrizes Curriculares para o Ensino Fundamental. Se a inclusão será na modalidade disciplina ou tema transversal, é assunto ainda indefinido.

Completamente distinta dessas propostas de caráter universalista é a aprovação de leis municipais de caráter particularista, a exemplo da inclusão de "noções sobre o Holocausto Nazista" como matéria extracurricular nas escolas de ensino médio do Estado do Rio de Janeiro, projeto de lei do vereador Gerson Bergher (PL-RJ). O projeto foi aprovado e sancionado pelo prefeito da capital fluminense, como lei n. 4.782/2008, mas foi declarado inconstitucional pelo Tribunal de Justiça estadual, por unanimidade de votos. A razão alegada pelos desembargadores foi a necessária decisão federal em matéria desse tipo. Outra iniciativa, dessa vez da vereadora Teresa Bergher, obteve sucesso com a sanção da lei municipal n. 5.267/2011. Além de proclamar que o disposto na lei não prejudicaria o conteúdo da disciplina de História, cujos conteúdos seriam fixados pelo Ministério da Educação (MEC), o Conselho Municipal de Educação deveria determinar a inclusão de "uma abordagem especial de noções sobre o holocausto nazista como forma de educação, prevenção e combate a todas as formas de discriminação e intolerância”. Escudada no reconhecimento da prioridade federal em matéria curricular, a lei de 2011 não sofreu arguição de inconstitucionalidade.

No ano anterior, a Câmara Municipal de Porto Alegre havia aprovado projeto de lei de autoria do vereador Valter Nagelstein (PMDB-RS), com idênticos propósito e artifício, isto é, a inclusão do tema holocausto nazista na disciplina de História. A inovação ficou na exigência de que o tema fosse sempre acompanhado de projeção de imagens.

Na contramão da vertente judaica, a Câmara dos Deputados formulou o projeto de lei n. 1.780/2011, oriundo da Ouvidoria Parlamentar, a partir de sugestões apresentadas por entidades da sociedade civil na Assembleia Legislativa do Rio de Janeiro, após e em reação a notícias na imprensa que vincularam o massacre de alunos em escola pública às ideias fundamentalistas islâmicas do assassino. $\mathrm{O}$ projeto de lei determina a inserção no currículo do ensino fundamental e médio de elementos da história dos povos árabes, a religiosidade islâmica e a contribuição dos povos árabes à sociedade contemporânea. Se aprovado o projeto, esse conteúdo deverá ser inserido em todas as disciplinas do currículo, em especial na Educação Artística, na Literatura e na História. 
Situada na fronteira entre o universalismo e o particularismo está a inclusão no currículo da educação básica de conteúdos referentes às culturas e etnias de origem africana e indígena. ${ }^{7}$ As leis n. 10.639/2003 e n. 11.645/2008 incluíram artigo na LDB determinando que nos estabelecimentos de ensino fundamental e médio, públicos e privados, fosse obrigatório o estudo da História afro-brasileira e indígena. ${ }^{8} \mathrm{O}$ conteúdo programático deverá incluir os

[...] diversos aspectos que caracterizam a formação da população brasileira, a partir desses dois grupos étnicos, tais como o estudo da História da África e dos africanos, a luta dos negros e dos povos indígenas no Brasil, a cultura negra e indígena brasileira e o negro e o índio na formação da sociedade nacional, resgatando as suas contribuições nas áreas social, econômica e política, à História do Brasil. (Lei $11.645 / 2008$, art. $1^{\circ}$, parágrafo $1^{\circ}$ )

Nenhuma das duas leis determinou a criação de disciplina específica, limitando-se a que os conteúdos mencionados sejam ministrados no âmbito de todo o currículo do ensino fundamental e médio, especialmente nas áreas de Educação Artística, Literatura Brasileira e História do Brasil.

A lei n. 1.639/2003 resultou de projeto da deputada Esther Grossi (PT-RS) em parceria com o deputado Bem-Hur Ferreira (PT-MS), e a lei n. 11.645/2008 originou-se de projeto da deputada Mariangela Duarte (PT-SP). A deputada Grossi elegeu-se deputada federal com o prestígio adquirido pelo projeto Escola Cidadã, que projetou a administração petista de Porto Alegre no cenário educacional, razão pela qual ela não pode ser qualificada de externa ao campo da educação. ${ }^{9}$

A Educação Ambiental é um tema que chega aos currículos escolares tanto da esquerda quanto da direita do espectro ideológico. Ao contrário das medidas concretas de proteção ao meio ambiente, quando se trata de educação o tema recebe apoios praticamente unânimes.

A lei n. 9.795/1999, aprovada a partir de projeto do deputado Fábio Feldman (PSDB-SP), determina que a Educação Ambiental seja componente "essencial e permanente" da educação nacional, devendo estar presente, de forma articulada, em todos os níveis e modalidades do processo educativo, em caráter formal e não formal. Não deve ser ministrada como disciplina específica dos currículos, mas, sim, constituir uma prática educativa. Os currículos dos

7 A amplitude e a duração da influência dessas culturas na formação da sociedade brasileira contrapõe-se à suposição de particularismo, o que não impede que as questões nelas implicadas sejam tratadas assim, levando até mesmo racismo reativo.

8 A primeira lei tratou apenas da História e da cultura dos afro-brasileiros, em função da maior força política dos movimentos negros. A segunda lei, aprovada cinco anos depois, corrigiu a defasagem, tratando, também, dos indígenas.

9 Para uma introdução a esse projeto, ver Moreira (2000). 
cursos de formação de professores devem incluir a Educação Ambiental, e os docentes em atividade na data da promulgação da lei deveriam receber formação complementar em suas áreas de atuação de modo que atendam aos princípios e objetivos da Política Nacional de Educação Ambiental.

Não satisfeito com o disposto na lei, o deputado José Linhares (PP-CE) apresentou à Câmara o projeto de lei n. 3.681/2008, que substitui o termo Educação Ambiental por Educação para o Desenvolvimento Sustentável. A prática educativa também não o agradou, razão pela qual a criação de disciplinas específicas foi prevista no projeto, como escreveu na justificação:

A criação de disciplinas no Ensino Básico em toda a rede de ensino e de uma disciplina de Ecologia para as Licenciaturas será uma providência de enorme valor para o enriquecimento e o preparo para os novos professores, no sentido de formar uma consciência e uma inteligência voltada para a educação de nossas crianças.

Antes dele, o deputado Dr. Evilásio (PSB-SP) havia apresentado a indicação n. 837/2000, sugerindo ao Poder Executivo, por intermédio do Ministério da Educação, a inclusão da disciplina Educação Ambiental no currículo do ensino fundamental. Mais ambicioso, o deputado José Carlos Coutinho (PFL-RJ) pretendeu, com o projeto de lei n. 3.728/2000, que essa disciplina fosse incluída nos currículos dos três níveis de ensino.

Em suma: religião, moral, ética, cidadania, civismo, direitos humanos, holocausto, cultura árabe, cultura afro-brasileira, cultura indígena, meio ambiente, aí está a maior parte dos temas objeto de inserções nos currículos escolares, produto da ação política de partidos ideológicos. ${ }^{10}$ Não foram produto da reflexão dos atores internos ao campo educacional, mas, sobretudo, vieram de fora dele. Mesmo quando o campo educacional se organiza e trata dessas questões, como na Conferência Nacional de Educação, realizada em março de 2010, a pressão externa já produzira seus efeitos práticos.

Levantamento realizado pela Ação Educativa, reputada ONG paulista, calculou em um quarto a fração do número dos projetos de lei sobre temas educacionais, em tramitação na Câmara dos Deputados e no Senado, que propunham a criação de novas disciplinas ou a mudança nos conteúdos do currículo escolar. $\mathrm{O}$ número desses projetos de lei chegava a 250 , em estudo finalizado em novembro de 2010. Precisa medida da falta de autonomia do campo educacional!

10 Como suas referências são externas ao campo educacional, esses proponentes desconhecem ou descartam os temas transversais dos Parâmetros Curriculares Nacionais do ensino fundamental e médio. 
Este item é encerrado com menção a entrevista da ex-deputada gaúcha Esther Grossi, coautora do projeto de lei que originou a lei n. 10.639/2003. Em entrevista à Rádio Guaíba, a propósito da lei recém-aprovada pela Câmara dos Vereadores de Porto Alegre, a ex-secretária municipal de Educação declarou-se contrária a essa providência, por entender não ser da competência do Poder Legislativo decidir o que deve ou não ser ensinado às crianças. Nas suas palavras:

Eu defendo que haja grandes pesquisadores da área da Educação que possam organizar os currículos, não porque o vereador disse, mas porque existe uma equipe com uma visão em rede do ensino. Embora eu tenha a maior simpatia de que não esqueçamos o horror que foi o Holocausto, incluir esse assunto obrigatoriamente é sempre uma visão deturpada da função do legislador. ${ }^{11}$

A posição da ex-secretária e ex-deputada estendeu-se, também, à lei n. 10.639/2003, já mencionada anteriormente.

\section{A VERTENTE ECONÔMICA}

Os sistemas educacionais, especialmente as redes públicas de ensino, constituem importantes mercados para a venda de mercadorias: de livros a computadores, de contratos de serviços para empresas privadas a reserva de local de trabalho para milhares de licenciados.

Com agrado ou com repulsa, é comum dizer-se que o currículo do ensino brasileiro é determinado pelo livro didático, não o contrário. Apesar das Diretrizes Nacionais Curriculares, o peso das editoras é determinante. Em 2010, o MEC despendeu um bilhão de reais na compra, avaliação e distribuição dos livros didáticos do Plano Nacional do Livro Didático (PNLD), compreendendo um total de 137,5 milhões de exemplares, para atender a 30 milhões de alunos. ${ }^{12}$ Esse montante corresponde a 54\% da produção nacional de livros (Britto, 2011, p. 12).

Não só pelo tamanho da população como também por sua organização, o Brasil é um dos mercados mais apetitosos do mundo para as editoras de livros. ${ }^{13}$ Mesmo com poucos livros lidos por habitante, o país tem seu grande atrativo no PNLD. Criado pelo decreto n. 91.592/1985, o Programa prevê a compra de livros de editoras sediadas no país para distribuição gratuita aos alunos do ensino fundamental. Desde o início

11 Disponível em:<www.correiodopovo.com.br/impresso.Aspx?Noticia=210159>. Acesso em: 15 jul. 2011..

12 Informações obtidas na página do Fundo Nacional do Desenvolvimento da Educação, a quem está afeto o PNLD. Disponível em: < www.fnde.gov.br/index.php/ programas-livro-didatico>.

13 Nossa referência principal é a tese de doutorado de Cristina de Figueiredo Cassiano sobre o mercado do livro didático no Brasil (2007). 
do programa, a escolha dos livros é feita pelos professores das escolas públicas, e a compra, pelo governo federal para entrega às escolas, conforme as opções prévias dos docentes. ${ }^{14} \mathrm{~A}$ não ser os destinados à Alfabetização, os livros são entregues gratuitamente aos alunos e recuperados para reutilização por três anos letivos consecutivos. Já que os livros são escolhidos pelos professores, não há exigência de licitação.

As expectativas suscitadas pelas primeiras providências foram no intuito de uma maior participação pública no programa. A Fundação de Assistência ao Estudante promoveu pesquisas e debates sobre o livro didático, em convênio com universidades, o que despertou a esperança de que elas participariam da elaboração de política para esse importante recurso pedagógico. "Esperava-se que se levasse em conta a liberdade de escolha do livro didático, a racionalidade da distribuição centralizada ou, pelo menos, centralmente coordenada, com a participação de entidades que congregavam educadores e de centros de estudos, na elaboração das listas de escolha e das editoras credenciadas" (Cunha, 1991, p. 277). Essas expectativas foram frustradas, pois o PNLD permaneceu um programa de compra de livros editados e produzidos por editoras privadas. O papel do governo permaneceu na busca de mecanismos de mercado, mediante a correção da oferta.

Dez anos depois de criado, o Programa passou a contar com previsão de recursos, o que assegurou um fluxo regular e a universalização da distribuição dos livros aos alunos do ensino de $1^{\mathrm{o}}$ grau. ${ }^{15}$ Depois de denúncias da existência de erros nos livros adquiridos, o governo federal passou a avaliá-los e somente a comprar os que fossem considerados adequados. O leque de disciplinas também foi ampliado. Além de Português e Matemática, foram beneficiadas a Alfabetização, a História, a Geografia e as Ciências, para as oito séries do ensino fundamental. Além dos livros reutilizáveis, também dicionários da língua portuguesa passaram a ser distribuídos aos alunos para uso individual. Em 1997, o PNLD foi completado com o Programa Nacional Biblioteca da Escola (PNBE), que visou, também, as escolas públicas de ensino fundamental, em moldes análogos àquele. Em 2003, o PNLD foi estendido ao ensino médio.

A avaliação, inicialmente realizada por especialistas contratados pelo MEC, entre os quais se incluíam autores de livros didáticos, passou a ser realizada por equipes técnicas das instituições públicas de ensino superior, uma para cada disciplina, mediante convênio com a Secretaria de Educação Básica do MEC.

No quadro das transformações econômicas do país, esse conjunto de programas reforçou duas mudanças que vinham ocorrendo no mercado editorial: a concentração das empresas produtoras de livros e sua internacionalização.

14 Cerca de $20 \%$ das escolas deixam de enviar suas opções ao Fundo Nacional de Desenvolvimento da Educação (FNDE), que opta por enviar as obras mais escolhidas na região de cada escola omissa.

15 A designação dos níveis educacionais segue a nomenclatura oficial de cada momento. 
As editoras que mais vendem para o PNLD formam um oligopólio. "Das 64 empresas que disputaram por uma fatia do mercado nos primeiros anos desse programa, somente 12 editoras permaneceram, e também houve casos de incorporação das menores editoras pelas maiores, além de contarmos com a entrada do Grupo Positivo" (Cassiano, 2007, p. 36). Em 2006, venderam mais de um milhão de livros ao PNLD as seguintes editoras: Ática, Brasil, FTD, IBEP, Moderna, Nova Geração, Positivo, Saraiva e Scipione.

Durante o governo FHC, grandes grupos editoriais espanhóis, que já estavam fortemente instalados em países da Hispano-América, desembarcaram no Brasil, cujo mercado correspondia a 40\% de toda a América Latina. Os espanhóis, que entraram fortemente na compra de estatais privatizadas nas áreas de energia, telecomunicações e bancos, também assumiram o controle de empresas privadas rentáveis, como na edição de livros.

O oligopólio dos livros didáticos passou por grandes mudanças. Assim concluiu Cristina Cassiano sobre o período observado pelo mercado livreiro no período 1985-2007:

[...] vimos o oligopólio no ramo dos didáticos passar das empresas familiares eminentemente nacionais (exceção feita à FTD) para o dos grandes grupos, sendo que o capital internacional num primeiro momento, foi representado pelas empresas espanholas, que já estavam instaladas nos demais países da América Latina e do Caribe. (idem, p. 207)

Ao contrário do que ocorre em países como o México, onde o Estado produz e distribui os livros didáticos para as escolas públicas, no Brasil esse enorme mercado ficou como que restrito às empresas privadas. Apesar de o país dispor de universidades e centros de pesquisa que figuram entre os mais importantes do mundo, inclusive ampla e qualificada pós-graduação, os professores e pesquisadores têm de recorrer às editoras privadas para que publiquem seus livros e os distribuam no setor público.

Como as editoras privadas ficam na dependência das indicações dos professores das redes públicas e privadas de ensino, as estratégias de divulgação adquirem fundamental importância e assumem distintas configurações conforme as regiões do país. No Sul e no Sudeste, as equipes de divulgação deixam os livros nas escolas públicas à espera da indicação, pois têm de dar atenção à rede privada, que é grande. No Norte e no Nordeste, a divulgação é mais agressiva, com a oferta de brindes e prêmios aos professores das redes públicas, já que a rede privada é menor. A disputa chegou a tal ponto que a portaria MEC n. 2.963/2005 instituiu normas de conduta para o processo de execução dos programas do livro didático.

Dois anos depois, a portaria normativa MEC n. 7/2007 ampliou as restrições para a divulgação das editoras, prevendo punições para o caso de descumprimento. A portaria visava, explicitamente, as editoras e seus representantes, bem como os autores de livros didáticos cujas obras tivessem sido selecionadas pelo PNLD e 
similares. Passemos à tipificação dos atos considerados transgressões: oferecer vantagens a pessoas ou instituições vinculadas ao processo de escolha, no âmbito dos programas, como contrapartida à indicação de livros ou materiais de sua titularidade; distribuir presentes ou brindes a pessoas ou instituições vinculadas ao processo de escolha, no âmbito dos programas; produzir e distribuir catálogo ou outro material com características gráficas ou outras características que induzam os professores a acreditar que se trata de material oficial, produzido pelo Fundo Nacional de Desenvolvimento da Educação (FNDE); utilizar logomarcas oficiais, selos dos programas, ou marcas e selos graficamente semelhantes, para efeito de propaganda, publicidade e divulgação, ou qualquer outro que induza ao entendimento de que se trata de material oficial do FNDE; distribuir exemplares de livros utilizados na divulgação, com textos ou imagens que induzam ao entendimento de que eles são indicados preferencialmente pelo MEC para adoção nas escolas, em detrimento de outros; utilizar, nas formas de divulgação, livros de conteúdo (imagens e textos) diferente dos livros inscritos e selecionados para os programas, bem como livros com especificações técnicas diferentes daquelas estabelecidas no edital; realizar pessoalmente a divulgação ou entrega de qualquer material de divulgação dos livros diretamente nas escolas, após a publicação do resultado da avaliação dos guias de escolha pelo FNDE, até o final do período de escolha pela internet e pelo formulário impresso, sendo permitida, durante esse período, a divulgação pelo envio de livros, catálogos, folders e outros materiais, exclusivamente por remessa postal, definida como a entrega de materiais de forma impessoal, pelos correios ou forma equivalente, sem a presença do editor ou seu preposto ou outrem com vínculo funcional evidente com o titular de direito autoral; realizar orientação pedagógica nas escolas ou Secretarias de Educação, após a publicação do resultado da avaliação ou a divulgação dos guias de escolha pelo FNDE até o final do período de escolha pela internet e pelo formulário impresso; imprimir informação na quarta capa dos livros utilizados na divulgação além do Hino Nacional e do número do ISBN, e imprimir qualquer informação na segunda e terceira capas desses livros; patrocinar, com qualquer quantia, material de propaganda (brindes, blocos, canetas, guardanapos etc.) ou qualquer outro benefício, os eventos relativos aos programas realizados pelas escolas ou Secretarias de Educação.

As reivindicações continuam, sempre no intuito de ampliar o tamanho das compras governamentais. Até agora, as editoras não conseguiram que fosse aceita sua reivindicação de suprimir o caráter reutilizável do livro, em proveito do consumível num mesmo ano letivo, o que daria um aumento de alguns milhões de livros adquiridos pelo governo federal.

Se o emprego dos livros didáticos não tem adversários no campo educacional, contando com aprovação geral, o mesmo não se dá com os equipamentos de informática, como os computadores. Seu emprego nas escolas é objeto de admiração ou de repulsa, passando pela posição intermediária de aceitação condicional ou 
desconfiada. O livro didático é um equipamento muito antigo, já naturalizado como auxiliar no ensino, já os computadores são muito recentes, apenas uma parcela dos docentes os conhecem, mesmo assim os empregam nos níveis mais elementares da potencialidade desses equipamentos.

Prevalece uma ideia mágica sobre os efeitos dos computadores nas escolas, a ponto de escolas privadas incluí-los como itens de propaganda. Não temos como propósito discutir o alcance nem os limites pedagógicos do uso da informática na educação escolar, mas, sim, o impulso conferido por essa ideia mágica, ingênua ou interessada, na compra de equipamentos e de programas pelos sistemas públicos de ensino.

A comparação internacional é o mote principal. Com a média de um computador para pouco mais de seis alunos da educação básica, o Brasil ocupa posição inferior à de muitos países, inclusive latino-americanos, como a Colômbia, que dispõe de uma máquina para quase três. A China oferece um computador para menos de dois alunos (1,75), e na Austrália praticamente empatam os números de máquinas e de estudantes. Com esses dados na mão, entusiastas pela "inclusão digital" e vendedores de equipamento têm base "objetiva" para a promoção de programas estatais de compra de computadores para distribuição às escolas públicas, nas quais os números são ainda mais desfavoráveis do que as médias já apontadas.

O entusiasmo dos propagandistas apressados dos computadores nas escolas não leva em conta que praticamente a metade dos alunos da educação básica não dispõe de computador em suas residências, nem que a existência desse equipamento em casa é um contraponto indispensável de seu uso nas escolas.

Advogados da informática nas escolas defendem que o uso dos computadores no ensino melhora o desempenho escolar, embora nem sempre se reconheça a interveniência das condições socioeconômicas dos alunos: a diferença de qualidade do ensino resulta do uso do computador pelas escolas ou os alunos de mais elevado nível de renda e acesso à cultura são os que também estudam em escolas que têm computadores? É a primeira relação que prevalece entre as administrações educacionais e fundamenta os programas de compra e distribuição de computadores.

O MEC montou o Programa Nacional de Tecnologia Educacional (PROINFO), que tem dois grandes objetivos: compra e distribuição de computadores para as escolas públicas e a capacitação de professores e gestores para o uso da informática. A meta é um computador por aluno, nome do projeto de sigla UCA. O Programa Banda Larga complementa aquele pela melhoria das conexões via internet. Nos últimos dez anos, o PROINFO adquiriu 84 mil laboratórios de informática e os distribuiu a 67 mil escolas, beneficiando 44 milhões de alunos.

A rede de ensino fundamental do município do Rio de Janeiro monta, desde 2010, a plataforma Educopédia, em parceria com o Núcleo de Computação Eletrônica da Universidade Federal do Rio de Janeiro (UFRJ), a Secretaria de Educação a Distância do MEC e parceiros privados. O projeto é baseado na instalação de um 
computador por aluno, professores e estudantes poderão acessar atividades autoexplicativas, não só nas salas e nas horas da aula. Cada sala de aula deverá dispor de internet, caderno virtual, datashow, um computador de mesa para o professor e um notebook para cada aluno. As aulas estarão prontas para uso na sala, por professor e alunos, o que permite que estes trabalhem mesmo se o professor estiver ausente. A Secretaria Municipal de Educação tem como meta distribuir 128 mil computadores para as escolas de ensino fundamental de sua rede.

Esse é um enorme mercado para os produtores e importadores de equipamentos de informática, que será ainda mais ampliado pela entrada dos tablets, que algumas instituições privadas já estão fazendo substituir livros e cadernos. Algumas universidades privadas já entregam aos alunos, "gratuitamente", tablets com as apostilas e outros materiais de uso didático e administrativo. A Coreia tem sido evocada como exemplo de país que não usa livros didáticos impressos, substituídos pelos tablets.

Uma realidade nova nas redes públicas de educação básica são os sistemas apostilados de ensino ou sistemas estruturados de ensino. Amplamente empregados nas instituições privadas, eles consistem na substituição de livros didáticos por um conjunto de materiais, principalmente publicações consumíveis (apostilas), de modo que cada aula esteja previamente preparada para os professores, bem como as avaliações.

Num primeiro momento, esses sistemas foram assumidos por instituições privadas de educação, compreendendo a compra de materiais pedagógicos e "pacotes" educacionais de grandes empresas, como COC, Objetivo, Positivo e Pitágoras, que incluem aluguel de marca, pelo mecanismo de franquias, avaliação e formação em serviço dos professores. Num segundo momento, essas empresas avançaram sobre os sistemas públicos de educação básica, vendendo sistemas de ensino para as redes municipais e estaduais. Mas, ao encontro dessa oferta, caminhou uma demanda ávida.

O estado de São Paulo parece ter sido o mais favorável para a ação dessas empresas, pela concentração das instituições privadas que atendem à população de renda mais alta, como, também, pela existência de municípios com elevada arrecadação tributária. Esse estado sempre se destacou, no conjunto da federação, pela peculiaridade de sua rede escolar estadual oferecer cerca de $90 \%$ das matrículas no ensino fundamental público, em contraste com outros, nos quais os municípios detinham maior participação nessa oferta. A criação do Fundo de Manutenção e Desenvolvimento do Ensino Fundamental e Valorização do Magistério (FUNDEF), por meio da emenda constitucional n. 14/96, levou a uma inversão tendencial desse quadro. A partir de 1997, os municípios passaram a organizar suas próprias redes escolares.

Pesquisa realizada por Theresa Adrião, Teise Garcia, Raquel Borghi e Lisete Arelaro mostrou que parte das prefeituras recorreu a empresas privadas para fazer frente ao novo quadro jurídico-político. 
[...] as perspectivas descentralizadoras, em geral, para esferas subnacionais impuseram a esses níveis de governo tarefas e atribuições que exigem, para além do repasse de recursos, condições de elaboração e implantação de políticas públicas. Como resposta a essas novas demandas, complexificadas pela diminuição dos aparatos técnicos, em virtude das reformas na administração pública ocorrida durante os anos de 1990, apresentam-se as parcerias com empresas privadas. (Adrião et al., 2009, p. 801)

Nesse processo, os pequenos municípios apresentaram condições mais adversas, do ponto de vista político e operacional, para a oferta educacional. Por essa razão, ficaram mais permeáveis à pressão de empresas vendedoras de sistemas de ensino. As consequências foram várias, dentre as quais sublinhamos a transferência de importante parcela das responsabilidades do poder público para o mercado. Em 2006, um quinto das redes municipais paulistas já tinha contratos com empresas vendedoras de sistemas apostilados.

Não se trata apenas da substituição de um meio de ensino por outro. Com os sistemas apostilados de ensino, entram nas redes públicas mais do que apostilas. As empresas vendedoras tendem a determinar não só os conteúdos a serem desenvolvidos pelos professores, mas também determinam os tempos de trabalho escolares, as rotinas e a própria metodologia do ensino. A aceitação tem sido grande. A propaganda apresenta os sistemas de ensino como trazendo para as redes públicas o sucesso das escolas privadas, que usam a mesma marca, mesmo que incompleta (cf Adrião et al., 2009, p. 812-813).

O grande expoente das vendas é o Grupo Positivo, que entra na disputa do mercado de livros por sua editora, a Nova Didática. Além de suas próprias instituições de ensino, nos três níveis, tinha, pela estimativa de Cassiano (2007, p. 193), mais de 2.200 escolas conveniadas, que matriculavam mais de 600 mil alunos. Além de atuar nos segmentos educacional e gráfico-editorial, o Grupo Positivo atua na informática, fabricando computadores, e já anuncia produzir tablets. Outras editoras passaram a atuar na oferta de sistemas apostilados por razões da lógica da concorrência setorial, como o Grupo Abril e a espanhola Santillana. Assim, os principais são: o Sistema de Ensino FTD, da Editora FTD; o Sistema UNO, da Editora Moderna; o Sistema SER, da Editora Ática/Scipione; o Sistema Agora, da Editora Saraiva; o Sistema Aprende Brasil, do Grupo Positivo; o Sistema de Ensino IBEP, da editora de mesmo nome.

Sobre a passagem da produção dos livros didáticos aos sistemas apostilados de ensino, o último parágrafo da tese de Cristina Cassiano diz:

Contraditoriamente, no início do século XXI, quando as normas governamentais endurecem no sentido de impor às editoras de didáticos normas legais para moralizar a divulgação dos livros didáticos nas escolas, ao que tudo indica, é quando os grandes grupos estão se relacionando com as escolas de forma muito 
mais visceral, com investidas de marketing agressivas e com a venda de produtos que, literalmente, determinam o currículo desenvolvido na rede pública, tais como a entrada dos sistemas de ensino na rede pública, os cursos para os professores, a promoção dos grandes eventos, configurando estes, entre outros, novos elementos na disputa pelo mercado nacional dos materiais didáticos, que na atual conjuntura foi ampliado para a formação de professores. Assim, todos esses elementos tensionam a questão dos limites entre o público e o privado e apontam para novas relações que doravante devem ser instauradas entre grandes grupos que dominam o setor dos didáticos e o Estado. (Cassiano, 2007, p. 202-203)

As editoras não se restringem à venda de livros didáticos, sistemas apostilados e computadores para uso das redes públicas de ensino. Uma delas, a Santillana, atua diretamente na promoção do ensino da Língua Espanhola.

O ensino dessa língua foi inserido obrigatoriamente pela lei n. 11.161/2005, a partir de projeto do deputado Átila Lira (PSDB-PI). O Espanhol é disciplina facultativa da $5^{\mathrm{a}}$ à $8^{\mathrm{a}}$ séries do ensino fundamental e obrigatória no ensino médio, com implantação gradual.

Embora a propaganda mencione como vantagem do ensino do Espanhol a integração do Brasil com os países de fala hispânica do MERCOSUL, a verdade é que a pressão pela inclusão dessa língua nos currículos escolares partiu das empresas espanholas que compraram empresas brasileiras, a exemplo do Banco Santander e da Editora Santillana. O banco custeou e o Instituto Cervantes executou a habilitação do magistério estadual paulista para o ensino dessa língua. A editora, por sua vez, beneficiou-se pela venda de livros para o ensino do Espanhol com o financiamento do PNLD (Cassiano, 2007, p. 177-178).

Também lucram com a venda de livros aos governos estaduais e municipais as editoras de livros confessionais, que produzem materiais para o Ensino Religioso nas escolas públicas. Embora o PNLD não inclua livros para essa disciplina, projetos de lei têm surgido no intuito de forçar a compra de material religioso pelas redes públicas estaduais e municipais.

Em meio à polêmica sobre a modalidade do Ensino Religioso, se confessional ou interconfessional, o município do Rio de Janeiro foi levado a adquirir material da primeira modalidade pela lei n. 4.635/2007. Ela determina que o material didático de utilização do Ensino Religioso seja fornecido pela prefeitura aos alunos. Somente poderão ser utilizados nessa disciplina livros, informativos, apostilas e outros que tenham a aprovação da autoridade religiosa responsável pelo credo de cada aluno. Resultado: um grande mercado aberto a editoras especializadas.

O Ensino Religioso nas escolas públicas constitui um mercado em disputa para licenciados. Enquanto na rede estadual paulista são os professores do quadro, licenciados em Filosofia, História ou Ciências Sociais, que ministram essa discipli- 
na, o estado do Rio de Janeiro abriu concurso para professor de Ensino Religioso para licenciados em qualquer disciplina do currículo, desde que tenham o endosso formal das instituições religiosas cujos credos pretendem ensinar.

Na busca da ampliação do mercado, o projeto de lei n. 309/2011, do pastor-deputado Marco Feliciano (PSC-SP), reserva o magistério do Ensino Religioso a quem possua pelo menos uma das seguintes habilitações: licenciatura em Ensino Religioso, Ciências da Religião ou Educação Religiosa. Caso o professor não tenha uma delas, valerá qualquer outra, desde que disponha alguma dose de religião inserida no histórico escolar ou curso adicional ministrado por entidade religiosa credenciada por Secretaria de Educação. Apesar de se tratar de disciplina facultativa, o projeto assegura isonomia de tratamento entre os professores de ensino religioso e os demais docentes das redes públicas de ensino.

Inserir em lei reserva de mercado de trabalho, como pretende o projeto do pastor-deputado, é um procedimento tão comum quanto garantido. Nas assembleias estaduais constituintes de 1989, várias unidades da federação tiveram suas constituições aprovadas com artigos que inseriam nos currículos escolares das redes públicas de $1^{\circ}$ e $2^{\circ}$ graus disciplinas como Filosofia e Sociologia.

A LDB-1996 determinou a inclusão de conhecimentos de Filosofia e de Sociologia como necessários ao exercício da cidadania (art. 36, parágrafo $1^{\circ}$, inciso III). Pressões locais, mediante previsão em constituição estadual ou fora dela, fizeram que em 2006 essas disciplinas integrassem os currículos do ensino médio de 17 unidades da federação, obrigatórias em 15 e optativas em dois (Parecer CNE/CEB n. 38/2006).

Dois anos depois, a lei n. 11.684/ 2008, resultante de projeto do deputado Ribamar Alves (PSB-MA), tornou obrigatório o ensino da Filosofia e da Sociologia em todas as séries do ensino médio de todo o país, nas escolas públicas e privadas, ministradas pelos licenciados nos cursos respectivos.

Assim se completa o esboço do panorama das interferências mercadológicas no campo educacional brasileiro, pela vertente econômica: não só a venda de mercadorias tangíveis - livros e computadores -, como também as intangíveis, a exemplo das metodologias de ensino e dos processos de avaliação. Ademais dessa modalidade de interferência econômica, a da venda de mercadorias, apontamos a reserva de mercado de trabalho para licenciados: Ensino Religioso, Ciências da Religião ou Educação Religiosa, Filosofia e Ciências Sociais ou Sociologia.

\section{PROSPECTIVA}

Atribuir à educação a solução de todos os males do país parece ser a grande unanimidade nacional. "Todos pela Educação" até virou nome de prestigiosa ONG.

Três ideias nos ocorrem como reação a essa exaltação.

Primeiro, o "entusiasmo pela educação", categoria de Jorge Nagle (1974) em seu magistral Educação e Sociedade na Primeira República. Hoje, como nos anos de 
1920, os resultados quantitativos são as marcas do desenvolvimento, da inclusão social e do combate à pobreza. Naquela época, Miguel Couto dizia que era preciso livrar o Brasil da mancha do analfabetismo. Hoje se diz que a educação é o grande motor do desenvolvimento e que a universidade é para todos. Parece importar menos que os alunos cheguem à $5^{\mathrm{a}}$ série do ensino fundamental sem saber ler ou sem compreender o que leem; que os "incluídos" em qualquer faculdade chamada de universidade recebam diplomas sem correspondência na formação profissional prometida; importa que os números cresçam e façam o país chegar mais perto dos países desenvolvidos, ao menos nas estatísticas.

Segundo, o caráter dissimulador desse entusiasmo, a ponto de obscurecer os verdadeiros problemas que impediram a escolarização das grandes massas, no Brasil de ontem, e a permanência e a progressão delas nas escolas do Brasil de hoje. A valorização mágica da educação como panaceia social transparece dos resultados da pesquisa de Elisa Reis (2000) sobre a percepção das elites brasileiras sobre a pobreza. Elas atribuíam à falta de educação do povo a responsabilidade pela maioria dos problemas do país, um artifício conveniente para não abrir mão de seus privilégios.

Terceiro, a contribuição que este artigo pretendeu trazer à compreensão das interferências dos mercados, em suas vertentes ideológica e econômica, nos currículos escolares. Mostramos como a débil autonomia do campo educacional propicia as interferências de diversos agentes, cada qual em busca de vantagens ideológicas, econômicas, frequentemente ambas. Essas interferências, por sua vez, dificultam o avanço do processo de autonomização do campo, acionando-se, em consequência, um movimento de ação recíproca viciosa que não propiciará, certamente, a ampliação nem a melhoria da educação brasileira, especialmente da educação pública, a mais vulnerável às tais interferências mercadológicas. $\mathrm{O}$ setor privado, particularmente o destinado à formação das elites, sempre soube cuidar de sua autonomia, atuando para dispor de bancada parlamentar e representação nos órgãos de deliberação coletiva dos sistemas educacionais.

Há seis décadas, os signatários do "Manifesto dos Pioneiros da Educação Nova" foram ingênuos em sua reivindicação de autonomia do campo educacional. Mas, de todo modo, eles procuraram elaborar uma posição nítida sobre a constituição do campo. Lamentavelmente, não temos hoje nada em seu lugar.

Nesse momento em que as energias da sociedade brasileira estão mobilizadas, esperançosamente, para a mudança, não seja este texto um elemento de freio, mas, sim, de impulso de transformação que evoque, em outros termos, o vetor autonomista do campo educacional.

Saber o que a autonomização não deve ser já é alguma coisa para começar. Antes de tudo, defesa da autonomia do campo educacional não significa a defesa do tecnicismo, essa concepção da educação que enfatiza os meios em detrimento da discussão dos fins e do contexto. A autonomia também não é sinônimo de cor- 
porativismo, expressão ampla que remete a interesses particularistas defendidos em nome de interesses coletivos.

Construir os parâmetros e os valores da autonomização é uma tarefa coletiva que envolverá, conflituosamente, sem dúvida, todos os participantes do campo, assim como todas as instâncias políticas do Estado brasileiro. Analisar e discutir as questões pertinentes ao campo educacional sem pressupostos, sem agentes nem temas sagrados nem interditados. Explicitar sempre os interesses implicados e as consequências de cada alteração proposta, o equivalente educacional do custo de oportunidade da Economia - o custo de uma política educacional em função de uma política alternativa renunciada.

Esse é um desafio imenso para as entidades e os indivíduos que integram o campo educacional. Melhor começar hoje, porque amanhã ele será ainda maior.

\section{REFERÊNCIAS}

Adrião, Theresa; Garcia, Teise; Borghi, Raquel; Arelaro, Lisete. Uma modalidade peculiar de privatização da educação pública: a aquisição de 'sistemas de ensino' por municípios paulistas. Educação E Sociedade, Campinas, n. 108, out. 2009.

Almeida, Vasni de. Ensino Religioso ou Educação Moral e Cívica: a participação de Guaraci Silveira na Assembleia Nacional Constituinte de 1933/34. Revista de Educação do Cogeime, São Paulo, ano 11, n. 21, dez. 2002.

Amaral, Daniela Patti. Ética, moral e civismo: difícil consenso. Cadernos de Pesquisa, São Paulo: Fundação Carlos Chagas, n. 131, maio/ago. 2007.

. Ética, cidadania, Educação Moral e Cívica: projetos de lei no Congresso Nacional. Disponível em: <http://www.nepp-dh.ufrj.br/ole/textos/daniela_etica.pdf>. Acesso em: 5/6/2011.

Bourdieu, Pierre. Questões de Sociologia. Rio de Janeiro: Marco Zero, 1983.

Britto, Tatiana Feitosa de. O livro didático, o mercado editorial e os sistemas de ensino apostilados. Centro de Estudos da Consultoria do Senado, 2011. Disponível em: <http:// www.senado.gov.br/senado/conleg/textos_discussao/TD92-TatianaFeitosadeBritto. pdf $>$. Acesso em: 5/7/2011.

Cassiano, Cristina de Figueiredo. O mercado do livro didático no Brasil: da criação do Programa Nacional do Livro Didático (PNLD) à entrada do capital internacional espanhol (1985-2007). Tese (Doutorado em Educação) - Pontifícia Universidade Católica de São Paulo, 2007.

Cunha, Luiz Antônio. Educação, Estado e democracia no Brasil. São Paulo: Cortez, 1991. . Os parâmetros curriculares para o Ensino Fundamental: convívio social e ética. Cadernos de Pesquisa, São Paulo, n. 99, nov. 1996. 
. O desenvolvimento meandroso da educação brasileira entre o Estado e o Mercado. Educaşão E Sociedade, Campinas, n. especial, 2007a.

. Sintonia oscilante: religião, moral e civismo no Brasil - 1931/1997. Cadernos de Pesquisa (São Paulo), no 131, maio/agosto 2007b.

Gramsci, Antonio. A concep̧ção dialética da história. Rio de Janeiro: Civilização Brasileira, 1978.

JACOB, Cesar Romero et al. Atlas da filiação religiosa e indicadores sociais no Brasil. São Paulo: Loyola, 2003.

Manifesto dos Pioneiros da Educação Nova. Revista Brasileira de Estudos Pedagógicos (Brasília), n. 150, maio/ago. 1984.

Moreira, Antonio Flávio Barbosa. Propostas curriculares alternativas: limites e avanços. Educação É Sociedade (Campinas), n. 73, dez. 2000.

NAgLe, Jorge. Educação e Sociedade na Primeira República. São Paulo: EPU/USP, 1974.

OliveIra, Romualdo Portela de. A transformação da educação em mercadoria no Brasil. Educaşão E Sociedade (Campinas), n. 108, out. 2009.

Peroni, Vera Maria Vidal; Oliveira, Regina Tereza Cestari de; Fernandes, Maria Dilnéia Espíndola. Estado e terceiro setor: as novas regulações entre o público e o privado na gestão da educação básica brasileira. Educação E Sociedade, Campinas, n. 108 , out. 2009.

ReIS, Elisa. Percepções da elite sobre pobreza. Revista Brasileira de Ciências Sociais, São Paulo, n. 42, fev. 2000.

Silva, Maria Vieira; Souza, Silvana Aparecida de. Educação e responsabilidade empresarial: "novas" modalidades de atuação da esfera privada na oferta educacional. Educação É Sociedade, Campinas, n. 108, out. 2009.

\section{SOBRE O AUTOR}

Luiz AntÔnio CunHa é doutor em educação pela Pontifícia Universidade Católica de São Paulo (PUC-SP). Professor titular da Universidade Federal do Rio de Janeiro (UFRJ).

E-mail: lacunha90@gmail.com 
to analyze to what extent the Brazilian educational standard would be compromising the country's development and how this, in its current state, affects the quality of education. It is, therefore, to analyze the potential and limits of education face the challenge of making Brazil a nation economically dynamic and socially equitable.

Keywords: education and development; centre-periphery relation; socioeconomic factors.

\section{Dimensiones estratégicas y limites del papel de la educación para el desarrollo brasileño}

El propósito mayor de este estudio es el de discutir la relación entre educación y desarrollo en el contexto actual de la sociedad brasileña, teniéndose en cuenta la condición sistemática de una economía altamente globalizada. Se parte de la premisa según la cual el desarrollo no es posible a todos los países, al menos en los padrones alcanzados en el llamado Primero Mundo, pero también se reconoce que el desarrollo de una nación no se concretiza sin una educación de calidad para todos. Se cuestiona el poder de transformación social que ha sido atribuido a la educación, una vez que ella propia es, en grande medida, derivada de las condiciones socioeconómicas. Se busca analizar en que medida el padrón de la educación brasileña estaría comprometiendo el desarrollo del país y cómo éste, en su etapa actual, afecta a la calidad de la educación. Se trata, pues, de analizar potencialidades y límites de la educación delante del desafio de convertir a Brasil en una nación económicamente dinámica y socialmente justa.

Palabras clave: educación y desarrollo; relación centro periferia; factores socioeconómicos.

\section{LUIZ ANTÔNIO CUNHA}

\section{Contribuição para a análise das interferências mercadológicas nos currículos escolares}

$\mathrm{O}$ artigo almeja contribuir para o conhecimento do modo como se definem os currículos escolares no Brasil, com ênfase no setor público. Assumindo o pressuposto de que a débil autonomia do campo educacional brasileiro propicia a intervenção de forças externas a ele, o texto identifica duas vertentes do mercado - a econômica e a ideológica - como relevantes para se entender a heteronomia do campo educacional. A vertente ideológica abrange a instrumentalização de instituições educacionais para a inculcação de valores e padrões de comportamento definidos como legítimos por entidades privadas, tais como as religiosas e as partidárias. A vertente econômica compreende tanto a venda de mercadorias para consumo das instituições educacionais (a oferta gerando a demanda), quanto a reserva de mercado para profissionais, empresas e organizações não governamentais. $\mathrm{O}$ autor reconhece que ambas as vertentes são úteis para efeitos analíticos, mas adverte contra sua 
reificação, já que os processos concretos não fazem tal distinção. Assim, a venda de mercadorias, a reserva de mercado e os projetos de socialização configuram os currículos escolares tão ou mais decisivamente do que os embates das concepções propriamente pedagógicas. O artigo conclui que a "invasão" do campo educacional pelos mercados dificulta a ampliação de sua autonomia, o que, por sua vez, facilita a "invasão", gerando um processo de ação recíproca viciosa.

Palavras-chave: política educacional; ideologia; mercado currículo; privatismo.

\section{Contribution to the analysis of market forces in school curriculum}

The article contributes to understanding how school curriculums are determined in Brazil, with an emphasis on the public sector. Assuming that the weak autonomy of the educational field in Brazil allows the intervention of forces external to it, the text identifies two market forces - the economic and the ideological - which are important in understanding the heteronomy of the educational field. The ideological element encompasses the instrumentalization of educational institutions to inculcate values and standards of behavior defined as legitimate by private entities, as well as religions and parties. The economic element includes both the sale of goods to be consumed by educational institutions (supply generating demand), as well as the market reserve for professionals, companies and non-governmental organizations. The author recognizes that both elements are useful for analytic purposes, but warns against their reification, given that the concrete processes do not make this distinction. Thus, the sale of goods, the reserve market and socialization projects shape school curriculum as much or more decisively than debates over pedagogical concepts. The article concludes that the "invasion" of the educational field by markets impedes the expansion of their autonomy, which, in turn, facilitates the "invasion," generating a vicious process of reciprocal action.

Keywords: educational policy; ideology; curricular market; privatization.

\section{Contribución para el análisis de las interferencias mercadológicas en los currículos escolares}

Este artículo desea contribuir para el conocimiento del modo como se definen los curriculos escolares en Brasil, con énfasis en el sector público. Se presupone que la débil autonomía del campo de la educación brasileña proporciona la intervención de fuerzas externas a él, el texto identifica dos vertientes del mercado - la económica y la ideológica como relevantes para entenderse la heteronimia del campo de la educación. La vertiente ideológica abarca la instrumentalización de instituciones educacionales para la imposición de valores y modelos de comportamiento definidos como legitimos por entidades privadas, tales como las religiosas y las partidarias. La vertiente económica comprende tanto la venta de mercaderias para el consumo de las instituciones educacionales (la oferta generando la demanda), cuanto la reserva de mercado para profesionales, empresas y organizaciones no gubernamentales. El autor reconoce que ambas vertientes son útiles para efectos analíticos, 
pero advierte contra su reificación, ya que los procesos concretos no bacen tal distinción. Asi , la venta de mercaderias, la reserva de mercado y los proyectos de socialización configuran los curriculos escolares tan o más decisivamente que los encuentros de las concepciones propiamente pedagógicas. El artículo concluye que la "invasión" del campo de la educación por los mercados, dificulta la ampliación de su autonomía, lo que, por su vez, facilita la "invasión", generando un proceso de acción recíproca viciosa.

Palabras clave: política educacional; ideología; mercado curriculo; privatización.

\section{MICHAEL F. D. YOUNG}

\section{O futuro da educação em uma sociedade do conhecimento: o argumento radical em defesa de um currículo centrado em disciplinas}

O texto focaliza o papel, na educação, do conhecimento em si. Argumenta que, para se dar um sentido sério à importância da educação, é fundamental tornar a questão do conhecimento foco central das análises no campo da educação, o que requer o desenvolvimento de uma abordagem do currículo baseada mais no conhecimento e na disciplina e menos no aprendiz e em seus interesses. Defende, ainda, que essa é uma opção radical.

$\mathrm{O}$ artigo sustenta que, em termos curriculares, não há nenhuma alternativa às disciplinas que se mostre adequada e que defina os conceitos que os alunos devem adquirir. Assevera, ainda, que o papel das escolas e do currículo centrado em disciplinas é bem mais complexo do que simplesmente manter desigualdades. Afirma que as disciplinas permitem que se ofereça aos alunos um conhecimento confiável. Por fim, considera que, embora as tendências globais possam prever mudanças nas ocupações, não se pode presumir que elas se aplicam à produção ou à aquisição do conhecimento confiável.

Palavras-chave: educação; currículo; conhecimento; disciplina.

The future of education in a society of knowledge: the radical argument in defense of a curriculum based on course content

This article focuses on the role of knowledge in education. It argues that to take serious account of the importance of education, it is essential to make the issue of knowledge central to analyses in the field of education. This requires the development of a curricular approach based more on knowledge and on course contents and less on the student and his or her interests. It also affirms that this is a radical option.

The article maintains that in terms of curriculum, there is no alternative to the course contents that prove to be suitable and which define the concepts that the students must acquire. It also asserts that the role of schools and of curriculum focused on courses is 